\title{
Differentiated vulvar intraepithelial neoplasia is often found in lesions, previously diagnosed as lichen sclerosus, which have progressed to vulvar squamous cell carcinoma
}

Hedwig P van de Nieuwenhof ${ }^{1}$, Johan Bulten ${ }^{2}$, Harrie Hollema ${ }^{3}$, Rianne G Dommerholt ${ }^{4}$, Leon FAG Massuger ${ }^{1}$, Ate GJ van der Zee ${ }^{5}$, Joanne A de Hullu ${ }^{1}$ and Leon CLT van Kempen ${ }^{2}$

${ }^{1}$ Department of Obstetrics and Gynecology, Radboud University Nijmegen Medical Centre, Nijmegen, The Netherlands; ${ }^{2}$ Department of Pathology, Radboud University Nijmegen Medical Centre, Nijmegen, The Netherlands; ${ }^{3}$ Department of Pathology, University Medical Centre Groningen, Groningen, The Netherlands; ${ }^{4}$ Department of Obstetrics and Gynecology, Jeroen Bosch Hospital, 's Hertogenbosch, The Netherlands and ${ }^{5}$ Department of Obstetrics and Gynecology, University Medical Centre Groningen, Groningen, The Netherlands

Lichen sclerosus is considered to be the precursor lesion of vulvar squamous cell carcinoma, of which only 2-5\% progress to squamous cell carcinoma. Differentiated vulvar intraepithelial neoplasia (VIN) has been proposed to be the direct precursor lesion, but this is a recently recognized, and a difficult to diagnose, entity, which may easily be mistaken for a benign dermatosis. The aim of this study was to test the hypothesis that of all lesions that have been diagnosed as lichen sclerosus in the past, a part might currently be diagnosed as differentiated VIN, and to identify histopathological differences between lichen sclerosus lesions with and without progression to vulvar squamous cell carcinoma. All lichen sclerosus slides were revised by two expert gynecopathologists and histopathological characteristics were documented. After revision of lichen sclerosus biopsies without progression $(n=61), 58$ were reclassified as lichen sclerosus. Revision of lichen sclerosus biopsies with progression yielded concordant diagnoses in 18 of 60 cases (30\%). Of 60 lesions, $25(42 \%)$ were reclassified as differentiated VIN. The median time from differentiated VIN to vulvar squamous cell carcinoma was shorter (28 months) than that from lichen sclerosus to vulvar squamous cell carcinoma (84 months) $(P<0.001)$. Lichen sclerosus that progressed to squamous cell carcinoma, but did not meet the criteria for differentiated VIN, more often showed parakeratosis $(P=0.004)$, dyskeratosis $(P<0.001)$, hyperplasia $(P=0.048)$ and basal cellular atypia $(P=0.009)$ compared with lichen sclerosus without progression. In conclusion, differentiated VIN diagnosis has been frequently missed and is associated with rapid progression to squamous cell carcinoma. Patients with lichen sclerosus with dyskeratosis and parakeratosis, hyperplasia and/or basal cellular atypia should be kept under close surveillance as these lesions also tend to progress to squamous cell carcinoma.

Modern Pathology (2011) 24, 297-305; doi:10.1038/modpathol.2010.192; published online 5 November 2010

Keywords: differentiated vulvar intraepithelial neoplasia; lichen sclerosus; vulvar squamous cell carcinoma

Correspondence: Dr HP van de Nieuwenhof, MD, Department of Obstetrics and Gynecology (791), Radboud University Nijmegen Medical Centre, PO Box 9101, 6500 HB Nijmegen, The Netherlands.

E-mail: H.Nieuwenhof@obgyn.umcn.nl

Received 1 June 2010; revised 2 August 2010; accepted 4 August 2010; published online 5 November 2010
Vulvar squamous cell carcinoma is the fourth most common type of gynecological cancer and affects the external female genitalia. It accounts for approximately $3-5 \%$ of all gynecological malignancies, with an incidence rate of 1-2/100 000. ${ }^{1}$ Vulvar squamous cell carcinoma is a disease that occurs in the sixth to seventh decade of life, and an increase in incidence is to be expected because of the aging of women. 
There are two different pathways leading to vulvar squamous cell carcinoma with their own premalignant lesions; the most common pathway, which accounts for $\sim 80 \%$ of all squamous cell carcinomas, is HPV independent, ${ }^{2}$ but its etiology is still unknown. These, mostly differentiated keratinizing, squamous cell carcinomas often arise in lichen sclerosus, and it has therefore been suggested that lichen sclerosus is the precusor lesion of squamous cell carcinoma. ${ }^{3-5}$ Lichen sclerosus is a chronic inflammatory skin disease and mainly affects the female anogenital area. ${ }^{6,7}$ The classical histological findings of lichen sclerosus are a thinned epidermis and/or the loss of rete ridges, hyperkeratosis, edema and/or hyalinization, as well as a chronic band-like inflammatory cell infiltrate of the dermis $^{8}$ (Figure 1a), but there are a lot of variations to these classical histological characteristics, leading to a myriad of lesions that may be classified as lichen sclerosus. Although lichen sclerosus is considered a premalignant condition, only $2-5 \%$ of patients with lichen sclerosus ultimately develop a vulvar squamous cell carcinoma. ${ }^{4,9}$ At present, no molecular markers have been proven to identify lichen sclerosus lesions that are at risk to develop vulvar squamous cell carcinoma.
It has been hypothesized more recently that differentiated vulvar intraepithelial neoplasia (VIN) is the direct precursor of vulvar squamous cell carcinoma. Differentiated VIN (Figure 3a) is often found directly adjacent to squamous cell carcinoma and is characterized by a thickened epithelium that is typically associated with the elongation and anastomosis of rete ridges (Figure $3 \mathrm{~b}$ ). Dyskeratosis and parakeratosis are usually present (Figures 3c and d), associated with prominent intercellular bridges (Figure 3b). Basal keratinocytes are large and pleomorphic with a relatively large amount of eosinophilic cytoplasm. Keratin pearl formation within the rete ridge may be seen. The nuclear chromatin is vesicular rather than coarse, and the nuclei have prominent nucleoli (Figure 3e), usually most prominently in the basal and parabasal keratinocytes. ${ }^{8}$ Although differentiated VIN is seen adjacent to $\sim 80 \%$ of vulvar squamous cell carcinomas, ${ }^{2}$ it is seldom diagnosed as a solitary lesion, ${ }^{10}$ which may be explained by underdiagnosis due to its difficult recognition ${ }^{11-13}$ or due to its short intraepithelial phase. ${ }^{10}$ It has been hypothesized that differentiated VIN may develop from lichen sclerosus and that it carries a higher malignant potential than lichen sclerosus does, ${ }^{3,13-17}$ but its
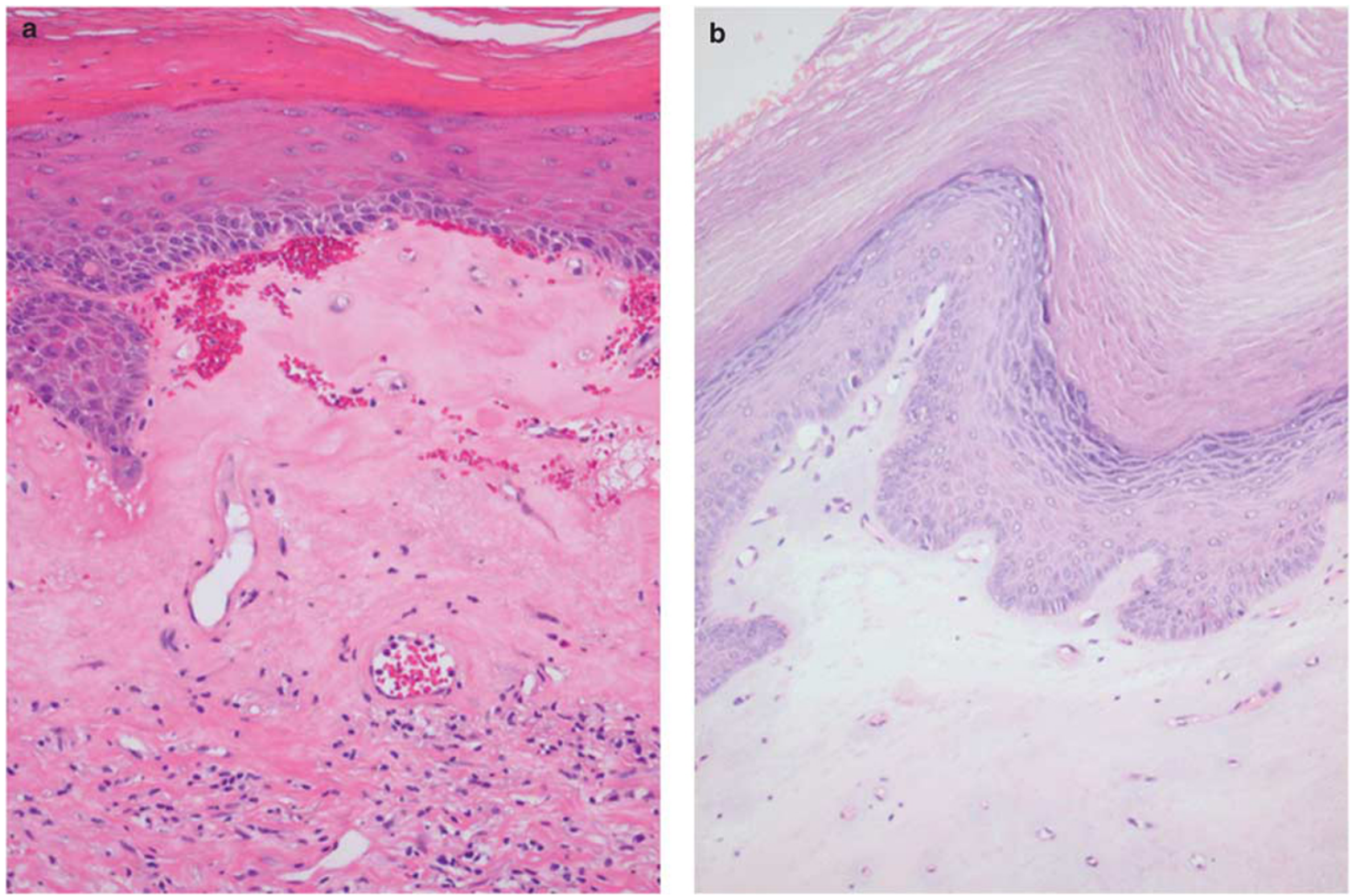

Figure 1 Classical cases of lichen sclerosus. (a) Typical example of lichen sclerosus with a thinned epidermis and a loss of rete ridges, hyperkeratosis, hyalinization and a chronic band-like inflammatory cell infiltrate of the dermis. (b) Lichen sclerosus with hyperkeratosis and hyperplasia. Original magnification, panels $\mathbf{a}$ and $\mathbf{b}: \times 100$. 
role as a premalignant lesion has not been accepted by all pathologists. ${ }^{18}$ We hypothesize that of all lesions that have been diagnosed as lichen sclerosus in the past, a substantial part might currently be diagnosed as differentiated VIN.

The terminology and criteria for the diagnosis of lichen sclerosus have been subjected to quite some revisions in the past 40 years, ${ }^{19,20}$ and this has unevitably led to the diagnoses of lichen sclerosus that would currently be classified differently, including differentiated VIN.

It is currently unknown which lichen sclerosus lesion carries the risk of malignant progression. This is in part due to the wide variety of histopathological entities that have been collectively diagnosed as lichen sclerosus in the past. The first aim of this study was to test the hypothesis that of all lesions that have been diagnosed as lichen sclerosus in the past, a part would currently be diagnosed as differentiated VIN. The second aim was to determine whether, in retrospect, there are histopathological differences between lichen sclerosus lesions that did and did not progress to vulvar squamous cell carcinoma. Recognition of the lichen sclerosus at risk for squamous cell carcinoma development would greatly help to select patients who need close follow-up.

\section{Patients and methods}

\section{Patient Selection}

\section{Lichen sclerosus without progression}

Patients with lichen sclerosus who were not diagnosed with a subsequent vulvar squamous cell carcinoma were selected from the vulvar outpatient clinic at the Department of Obstetrics and Gynecology of the Radboud University Nijmegen Medical Centre (The Netherlands). We used the nationwide Netherlands database of Cytopathology and Histopathology (PALGA) ${ }^{21}$ to confirm that these patients did not develop a vulvar squamous cell carcinoma with a minimum follow-up of 10 years.

\section{Lichen sclerosus with progression}

Patients with vulvar squamous cell carcinoma who were treated at the Departments of Obstetrics and Gynecology of the Radboud University Nijmegen Medical Centre or at the University Medical Centre Groningen between 1 January 1988 and 31 December 2008 were selected for this study. Using PALGA, all previous vulvar biopsies with the diagnoses 'Lichen Sclerosus (et atrophicus)' and 'vulvar dystrophy' were retrieved. When multiple previous biopsies were available from different moments, the most recent biopsy was included for this study (with a minimum interval between the biopsy and vulvar squamous cell carcinoma of 3 months). In case multiple biopsies were taken at the same time, the lesion with the most severe dysplastic characteristics was selected.
The hematoxylin and eosin (H\&E)-stained slides were retrieved and reviewed by two expert gynecopathologists (JB and $\mathrm{HH}$ ) independently and unaware of the course of the patient. Discrepancies were resolved in a consensus meeting with these two gynecopathologists. In the analyses, we categorized the diagnoses of vulvar dystrophy and lichen sclerosus together, because in earlier days, the term 'vulvar dystrophy' was used for the same entity as lichen sclerosus. Concordance between the original and revised diagnosis was calculated.

\section{Collected Data}

Patients' age, time of diagnosis of squamous cell carcinoma and time to progression were obtained from medical charts and electronic patient files. All slides were scored on the presence of hyperkeratosis, parakeratosis (Figures $1 \mathrm{~b}$ and 3d), dyskeratosis (Figure 3c), hyperplasia (Figure 1b), basal cellular atypia (Figure 2), presence of mitotic figures (Figure 3f), edema, hyalinization (Figure 1a) and presence of subepithelial inflammation (Figure 1a). In addition, we examined the presentation of rete ridges (Figure 3b), basal cell layer (Figure 3c) and epithelial thickness.

\section{Statistical Analysis}

Calculations were performed using Statistical Package for Social Sciences 16.0 (SPSS, Chicago, IL, USA).

Descriptive statistics were used to reproduce study results as percentages, means, medians and s.d. $\chi^{2}$-Tests were used to identify significant differences between lichen sclerosus with and without progression. The independent-samples $t$-test was used to compare the age for two groups. $P$-values $<0.05$ were considered to be statistically significant.

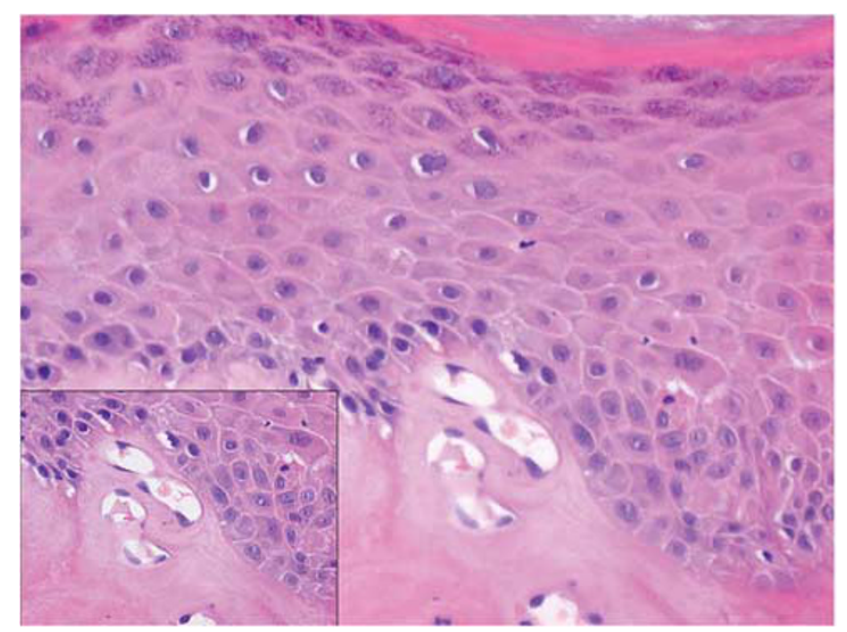

Figure 2 Lichen sclerosus with basal cell atypia. Lichen sclerosus with basal cell atypia (original magnification, $\times 200$ ), inset: magnification $\times 400$. 

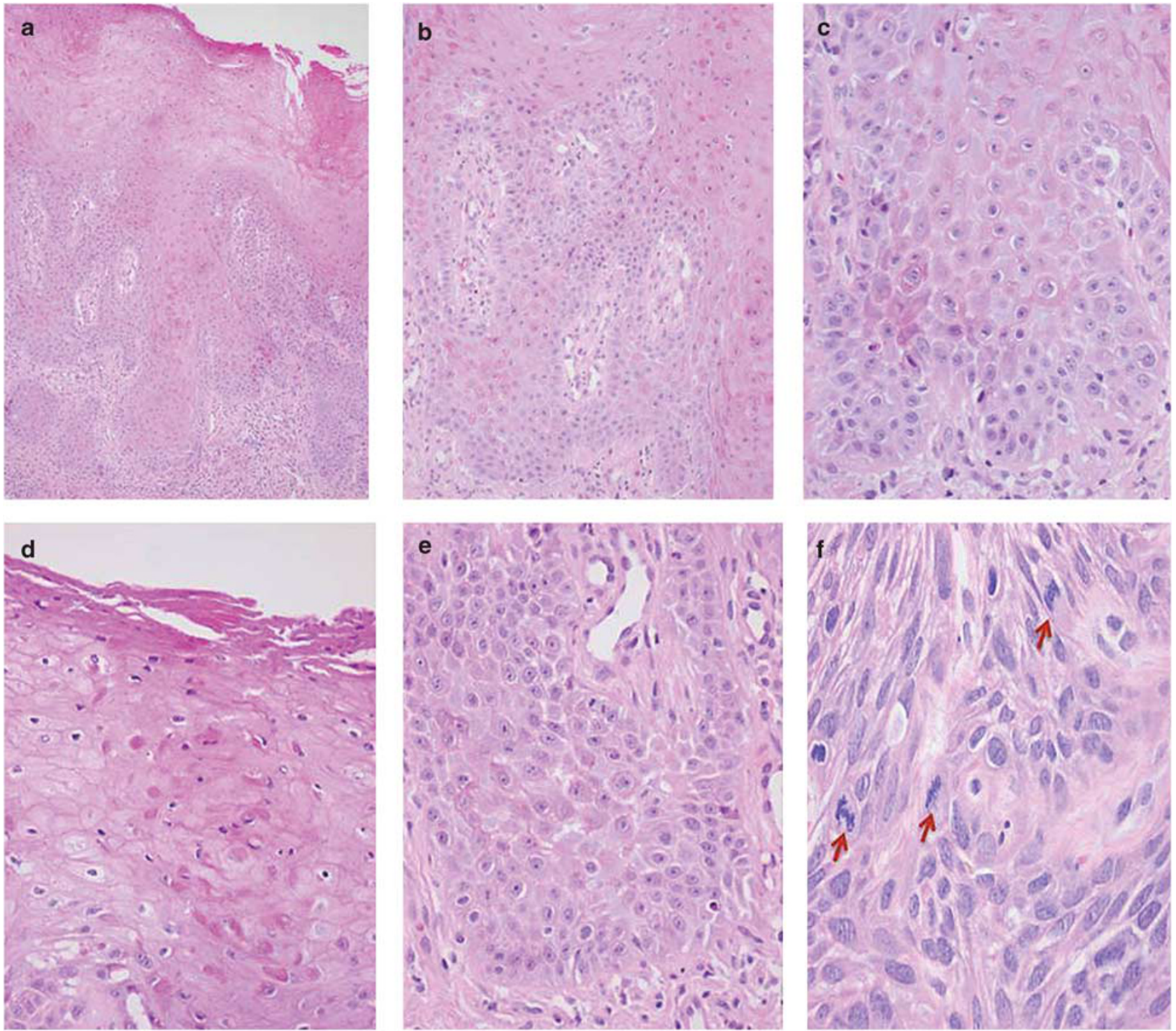

Figure 3 Differentiated vulvar intraepithelial neoplasia. Low-power overview of differentiated VIN (a) with the five most important histopathological characteristics that can be recognized in an H\&E stain: elongated rete ridges with anastomosis (b), disorderly basal cell layer and dyskeratosis (c), parakeratosis (d), prominent nucleoli (e) and atypical mitoses, indicated by arrows (f). Original magnifications: $\times 50$ (panel a), $\times 100$ (panels b and d), $\times 200$ (panels $\mathbf{c}$ and $\mathbf{e}$ ) and $\times 400$ (panel f).

\section{Results}

\section{Lichen Sclerosus without Progression}

A total of 61 patients with lichen sclerosus without progression and a minimal follow-up of 10 years were retrieved from the pathology archives of the Radboud University Nijmegen Medical Centre. The median age at the time of diagnosis was 59.5 years (range 16-83 years). Three biopsies did not fulfill the criteria for lichen sclerosus and were excluded. In 58 of the 61 cases (95\%), the diagnosis was not changed.

\section{Lichen Sclerosus with Progression}

During the study period 1988-2008, 273 patients with vulvar squamous cell carcinoma were treated in Nijmegen and 548 patients were treated in Groningen. In Nijmegen, 33 cases that met the criteria of a previous biopsy with 'Lichen Sclerosus (et atrophicus)' or 'vulvar dystrophy' were identified and 72 in Groningen. Of these 105 cases, a total of 60 biopsies were received from the pathology archives of the Radboud University Nijmegen Medical Centre/University Medical Centre Groningen and from the referring hospitals in the surrounding areas. We did not receive the 35 biopsies that we requested from the hospitals where the biopsies were taken, and 10 biopsies were excluded from analyses for different reasons (poor quality H\&E staining $(n=6)$ or slides with too little tissue to review $(n=4)$ ). The study population consisted of 60 lichen sclerosus patients with progression to vulvar squamous cell carcinoma. The median age at the time of diagnosis 
Table 1 Overview of original and revised diagnoses

\begin{tabular}{|c|c|c|c|c|c|c|c|c|}
\hline \multirow[b]{2}{*}{ Original diagnosis } & \multirow[b]{2}{*}{$\mathrm{n}$} & \multicolumn{7}{|c|}{ Diagnosis after revision } \\
\hline & & $L S$ & $\begin{array}{c}\text { LS with } \\
\text { hyperplasia }\end{array}$ & $\begin{array}{l}\text { LS with } \\
\text { atypia }\end{array}$ & $\begin{array}{c}L S \text { with hyperplasia } \\
\text { and atypia }\end{array}$ & $d V I N$ & Other & $\begin{array}{c}\text { Concordance } \\
\mathrm{n}(\%)\end{array}$ \\
\hline Lichen sclerosus & 42 & 18 & 4 & 3 & 1 & 10 & $6^{\mathrm{a}}$ & $18 / 42(42.9)$ \\
\hline LS with HPV-related lesion & 5 & & & & 1 & 4 & & $0 / 5$ \\
\hline LS with atypia & 4 & & & & & 4 & & $0 / 4$ \\
\hline LS with hyperplasia & 9 & 1 & & 1 & & 7 & & $0 / 9$ \\
\hline Total & 60 & 19 & 4 & 4 & 2 & 25 & 6 & 18/60 (30) \\
\hline
\end{tabular}

${ }^{\mathrm{a}}$ No LS, no dVIN. No LS, aspecific inflammation. Verrucous lesion, HPV induced: vulvar hyperplasia. Hypertrophy and hyperkeratosis: minimal aspecific inflammation, normal.

Table 2 LS with progression; diagnoses after revision by two expert gynecopathologists

\begin{tabular}{|c|c|c|c|}
\hline Diagnosis after revision & & $\begin{array}{c}\text { Median age } \\
\text { (years) (range) }\end{array}$ & $\begin{array}{l}\text { Median time to vulvar } \\
\text { SCC (months) (range) }\end{array}$ \\
\hline Lichen sclerosus & 29 & $64.6(30-90)$ & $84(9-230)$ \\
\hline Lichen sclerosus & 19 & $67.6(52-79)$ & $61(9-200)$ \\
\hline Lichen sclerosus with hyperplasia & 3 & $51.8(30-54)$ & $99(13-135)$ \\
\hline Lichen sclerosus with atypia & 5 & $59.1(53-64)$ & $115(91-231)$ \\
\hline Lichen sclerosus with hyperplasia and atypia & 2 & $69.7(65-73)$ & $30(26-35)$ \\
\hline Differentiated VIN & 25 & $64.4(42-90)$ & $28(5-144)$ \\
\hline No lichen sclerosus, no differentiated VIN & 6 & $64.0(54-72)$ & $31(4-63)$ \\
\hline
\end{tabular}

of lichen sclerosus was 64.6 years (range 30-90 years). These patients were older than were lichen sclerosus patients without progression $(P<0.001)$.

All biopsies were revised and scored. In total, diagnoses of 42 biopsies were changed by the two expert gynecopathologists (70\%). Of the $60(42 \%)$ lesions, 25 were previously diagnosed as lichen sclerosus, but that did progress to squamous cell carcinoma, were reclassified as differentiated VIN (Figure 3). The biopsies that were changed into differentiated VIN mainly came from the original diagnosis categories of lichen sclerosus with an associated lesion such as an HPV-induced lesion (VIN I, III, Morbus Bowen, Buschke Löwenstein), or from lichen sclerosus with hyperplasia, atypia or both. The highest percentage of concordance between the original and changed diagnoses was achieved for 'simple' lichen sclerosus without an associated lesion (43\%). The original and revised diagnoses are given in Table 1. Of all biopsies, six were not classified as lichen sclerosus/differentiated VIN. A total of 29 biopsies were diagnosed as lichen sclerosus, of which 1 was classified as early lichen sclerosus (categorized as lichen sclerosus), ${ }^{22}$ and 3 were classified as lichen sclerosus with hyperplasia (Figure 1b). Five lichen sclerosus biopsies had basal cellular atypia (Figure 2), and two biopsies were classified as lichen sclerosus with hyperplasia and basal cellular atypia. These seven biopsies did not comply with other criteria for differentiated VIN.

Differences in the time to progression into vulvar squamous cell carcinoma between lichen sclerosus and differentiated VIN biopsies were calculated. For this analysis, the six biopsies without lichen sclerosus or differentiated VIN were excluded. The time to progression for differentiated VIN (28 months) was shorter than that for lichen sclerosus (84 months) $(P=0.001)$ (Table 2). The number of lesions in the subcategories of lichen sclerosus was too small to calculate differences in times until progression.

\section{Histopathological Differences Between Lichen Sclerosus with and without Progression}

For this comparison, only biopsies that were indeed classified as lichen sclerosus after revision were included (29 with progression, 58 without progression). Lichen sclerosus biopsies with progression showed more often dyskeratosis (31 vs $0 \% P<0.001$ ) and parakeratosis (48 vs $19 \% P=0.004$ ) than did lichen sclerosus biopsies without progression. In addition, lichen sclerosus biopsies with progression more often had hyperplasia (24 vs 9\% $P=0.048$ ) and basal cellular atypia (21 vs $3 \% P=0.009)$. The other histopathological characteristics did not differ between both groups (Table 3).

\section{Discussion}

In this study, we found that $42 \%$ of lichen sclerosus biopsies, taken from patients who showed progression into vulvar squamous cell carcinoma, showed the histological characteristics of differentiated VIN. In the majority of cases, differentiated VIN was 
Table 3 Histopathological differences between LS with and without progression

\begin{tabular}{|c|c|c|c|}
\hline $\begin{array}{l}\text { Histological } \\
\text { features }\end{array}$ & $\begin{array}{l}\text { LS without } \\
\text { progression } \\
(\mathrm{N}=58) \\
\text { Number }(\%)\end{array}$ & $\begin{array}{c}L S \text { with } \\
\text { progression } \\
(\mathrm{N}=29) \\
\text { Number }(\%)\end{array}$ & P-value \\
\hline \multicolumn{3}{|l|}{ Hyperkeratosis } & 0.875 \\
\hline No & $21(36)$ & $11(38)$ & \\
\hline Yes & $37(64)$ & $18(62)$ & \\
\hline \multicolumn{3}{|l|}{ Parakeratosis } & 0.004 \\
\hline No & $47(81)$ & $15(52)$ & \\
\hline Yes & $11(19)$ & $14(48)$ & \\
\hline \multicolumn{3}{|l|}{ Dyskeratosis } & $<0.001$ \\
\hline No & $58(100)$ & $20(69)$ & \\
\hline Yes & $0(0)$ & $9(31)$ & \\
\hline \multicolumn{3}{|l|}{ Rete ridges } & 0.235 \\
\hline Normal & $2(3)$ & $5(7)$ & \\
\hline Reduced & $51(88)$ & $21(83)$ & \\
\hline Widened & $4(7)$ & 0 & \\
\hline Merged & $1(2)$ & $1(3)$ & \\
\hline $\begin{array}{l}\text { Elongated } \\
\text { and merged }\end{array}$ & 0 & $1(3)$ & \\
\hline $\begin{array}{l}\text { Widened } \\
\text { and merged }\end{array}$ & 0 & $1(3)$ & \\
\hline \multicolumn{3}{|c|}{ Epithelial thickness (cells) } & 0.332 \\
\hline$<5$ & $1(2)$ & $1(3)$ & \\
\hline $5-9$ & $27(47)$ & $10(35)$ & \\
\hline $10-14$ & $24(41)$ & $11(38)$ & \\
\hline $15-19$ & $5(9)$ & $4(14)$ & \\
\hline$\geq 20$ & $1(2)$ & $3(10)$ & \\
\hline \multicolumn{3}{|l|}{ Hyperplasia } & 0.048 \\
\hline No & $53(91)$ & $22(76)$ & \\
\hline Yes & $5(9)$ & $7(24)$ & \\
\hline \multicolumn{3}{|l|}{ Dysplasia } & 0.213 \\
\hline No & $57(98)$ & $27(93)$ & \\
\hline Yes & $1(2)$ & $2(7)$ & \\
\hline \multicolumn{3}{|c|}{ Basal cellular atypia } & 0.009 \\
\hline No & $56(97)$ & $23(79)$ & \\
\hline Yes & $2(3)$ & $6(21)$ & \\
\hline \multicolumn{3}{|l|}{ Mitotic figures } & 0.510 \\
\hline No & $49(85)$ & $26(90)$ & \\
\hline Yes & $9(15)$ & $3(10)$ & \\
\hline \multicolumn{3}{|l|}{ Basal cell layer } & 0.600 \\
\hline Normal & $52(90)$ & $27(93)$ & \\
\hline Disorderly & $6(10)$ & $2(7)$ & \\
\hline \multicolumn{3}{|l|}{ Edema } & 1.000 \\
\hline No & $22(38)$ & $11(38)$ & \\
\hline Yes & $36(62)$ & $18(62)$ & \\
\hline \multicolumn{3}{|l|}{ Hyalinization } & 0.099 \\
\hline No & $12(21)$ & $2(7)$ & \\
\hline Yes & $46(79)$ & 27 (93) & \\
\hline \multicolumn{3}{|c|}{ Inflammation at the epithelial-dermal junction } & 0.658 \\
\hline Absent & $22(38)$ & $9(31)$ & \\
\hline Focal & $12(21)$ & $5(17)$ & \\
\hline Diffuse & $24(41)$ & $15(52)$ & \\
\hline \multicolumn{3}{|c|}{ Inflammation subepithelial } & 0.647 \\
\hline Band-like & $25(43)$ & $14(48)$ & \\
\hline Not band-like & $33(57)$ & $15(52)$ & \\
\hline \multicolumn{3}{|c|}{ Intraepithelial presence inflammation cells } & 0.759 \\
\hline No & $24(41)$ & $13(45)$ & \\
\hline Yes & $34(59)$ & $16(55)$ & \\
\hline
\end{tabular}

found in biopsies of which the original diagnosis was lichen sclerosus with an HPV-induced lesion or with hyperplasia and/or atypia. In addition, we found that lichen sclerosus biopsies with dyskeratosis and parakeratosis, hyperplasia and atypia may be regarded as lichen sclerosus with an elevated risk of vulvar squamous cell carcinoma development.

By revising numerous biopsies that were earlier classified as lichen sclerosus, we show that a substantial part nowadays would be diagnosed as differentiated VIN. Remarkably, most revisions were made when the original report mentioned lichen sclerosus with an associated lesion (an HPV-induced lesion, hyperplasia and/or atypia) (Table 1). Most concordance was achieved for 'simple' lichen sclerosus lesions without an associated lesion. The histological diagnosis of differentiated VIN is difficult; the recognition of differentiated VIN is hindered by a high degree of cellular differentiation combined with an absence of widespread architectural disarray, nuclear pleomorphism and diffuse nuclear atypia. ${ }^{12}$ The atypia in differentiated VIN lesions is strictly confined to the basal and parabasal layers of the epithelium. ${ }^{8,12}$ In addition, despite the fact that differentiated VIN was first described in the 1960s by $\mathrm{Abell}^{23}$ as a highly differentiated form of vulvar carcinoma in situ, until more recently, the entity has not gained wide attention because its existence as a clinicopathological entity has long been questioned. ${ }^{18}$ As more insight is gained that vulvar squamous cell carcinomas originate from two different pathways, each with its own premalignant lesions, ${ }^{24,25}$ differentiated VIN has been designated the direct precursor of the HPV-independent pathway. Earlier, all VIN lesions were classified as being HPV related, which explains the high incidence of lichen sclerosus with HPV-induced lesions, which turned out to be differentiated VIN instead of the nowadays socalled usual VIN lesions. ${ }^{26}$ In addition to the difficult histopathological diagnosis, it is believed that the intraepithelial period of differentiated VIN is short, all being reasons why differentiated VIN has been seldom diagnosed as a solitary lesion. In this study, we show that differentiated VIN is not as rare as a solitary lesion as previously believed, but there is significant underdiagnosis. The recognition of differentiated VIN is of utmost importance because the malignant potential of differentiated VIN is considered to be high, ${ }^{10}$ and therefore, treatment differs between lichen sclerosus (topical superpotent corticosteroid ointment ${ }^{27}$ ) and differentiated VIN (surgical excision ${ }^{7}$ ).

After exclusion of lesions that were changed into differentiated VIN, we found that lichen sclerosus biopsies with progression more often showed dyskeratosis and parakeratosis, hyperplasia and basal cellular atypia in comparison with lichen sclerosus biopsies without progression. It has been suggested that hyperplasia, dysplasia or cellular 
atypia are precursor features linking progression of vulvar lichen sclerosus to vulvar squamous cell carcinoma $^{9,14,28,29}$ and that squamous cell hyperplasia with atypia might represent a step in the carcinogenesis towards vulvar squamous cell carcinoma. ${ }^{30}$ Although the numbers of lichen sclerosus lesions with atypia or hyperplasia were small in our study, it may be recommended that these patients require a more careful follow-up because they have a higher risk of developing vulvar squamous cell carcinoma. ${ }^{29}$ The characteristics of dyskeratosis and parakeratosis have not been associated with progression towards vulvar squamous cell carcinoma before, but were not included in the analyses of earlier studies. In our study, dysplasia was not a characteristic of lichen sclerosus biopsies with progression. We hypothesize that in studies that have defined features linking progression of lichen sclerosus to squamous cell carcinoma, differentiated VIN lesions may have also been included, and therefore, dysplasia was found to be associated with progression. Patients with progression were significantly older at the time of the biopsy, which has also been associated with malignant progression in other studies, ${ }^{28,29}$ but the difficulty is that it is unknown for how long the patients have been suffering from lichen sclerosus at the time of the biopsy.

From this study, we cannot draw strong conclusions regarding the malignant potential of differentiated VIN because we have not included differentiated VIN lesions without progression. In the lichen sclerosus group without progression, no differentiated VIN lesions were found. In an earlier study, we saw that $33 \%$ of solitary differentiated VIN lesions progressed to vulvar squamous cell carcinoma. ${ }^{10}$ In that study, we only used the reports in the PALGA database; we did not revise the VIN lesions. Now that we demonstrate that differentiated VIN is more often present in its solitary form than previously believed, its high malignant potential should be appreciated. The median time between differentiated VIN biopsies and vulvar squamous cell carcinoma development in this study was 28 months, which is comparable with the 23 months in our other study. ${ }^{10}$ In total, we have identified 92 (67 (van de Nieuwenhof et $a l^{10}$ ) and 25 (this study) solitary differentiated VIN lesions with and without progression, respectively, which is still a rather small number to draw strong conclusions from.

This study has several limitations; the first is the possible different localization of the biopsies and the subsequent squamous cell carcinoma. We do not have access to these data of patients as this is poorly recorded. The concept of field cancerization is plausible, because in most patients, the greatest part of the vulva is affected by lichen sclerosus. However, it is unknown whether different types of lichen sclerosus were present in one patient at the same time. In addition, there is a large time range between lichen sclerosus lesions and vulvar squamous cell carcinoma development, the longest being 19 years.
Moreover, two different populations were compared: women with known vulvar squamous cell carcinoma and in retrospect their biopsies with lichen sclerosus, and prospectively followed lichen sclerosus patients without progression to vulvar squamous cell carcinoma. It may have been that the clinical presentation of these two groups of women was different, but we do not have access to their medical files.

In total, 821 patients were treated for a vulvar squamous cell carcinoma during the study period, and of only 105 patients, a biopsy of lichen sclerosus or vulvar dystrophy was identified. We used PALGA, ${ }^{21}$ which has national coverage from 1992 onward, so it may be that more biopsies were taken before 1992, which we did not retrieve. However, the majority of vulvar squamous cell carcinoma patients do not have a recorded and histopathologically proven history of lichen sclerosus, but suffer from lichen sclerosus, either asymptomatic or unnoticed. ${ }^{4,28,31-33}$ This may result in delayed diagnosis by both patients and doctors. In our vulvar clinic, the policy is to biopsy every woman with a suspicion of lichen sclerosus, because this diagnosis has the consequence of a lifelong follow-up (at least yearly).

In this study, we solely studied the histopathological characteristics of differentiated VIN lesions, but using immunohistochemistry, it may be more easy to recognize differentiated VIN. In our study about the p53 expression of both lichen sclerosus and differentiated VIN, it turned out that the mean percentage of p53-positive cells was $\sim 50 \%$, and confined to the lower one-third of the epithelium, sometimes with suprabasal extension. This is contrast to lichen sclerosus, of which the percentage of p53-positive cells did not exceed 30\%. ${ }^{16}$

In conclusion, we found that in patients with progression, the original diagnosis of lichen sclerosus was often revised into differentiated VIN. When adhering to strict criteria (elongated rete ridges with anastomosis, a disorderly basal cell layer, dyskeratosis and parakeratosis, prominent nucleoli and atypical mitosis), the diagnosis of differentiated VIN should be more easy to make, especially when the patient is suffering from lichen sclerosus as well. We conclude that differentiated VIN suffers from underdiagnosis rather than from rarity. When the diagnosis of lichen sclerosus with an HPV-associated lesion, atypia or hyperplasia is made by a pathologist, the diagnosis of differentiated VIN should at least be considered by both the pathologist and the gynecologist/dermatologist. Furthermore, when the diagnosis of differentiated VIN cannot be established, but when lichen sclerosus with dyskeratosis and/or parakeratosis, hyperplasia and basal cellular atypia is diagnosed, close follow-up of the patient is warranted as these lichen sclerosus lesions are at increased risk for malignant progression. A prospective study and translational research are required to confirm our hypothesis that 
patients with lichen sclerosus lesions with dyskeratosis and/or parakeratosis, hyperplasia and basal cellular atypia are at risk of developing vulvar squamous cell carcinoma.

\section{Acknowledgements}

We thank the following pathological archives for sending in their slides, Medisch Laboratorium Stichting Pathologisch Laboratorium Assen/Emmen; Laboratorium voor Klinische Pathologie, Deventer Ziekenhuis; Centrum Pathologie, Martini Ziekenhuis Groningen; Kennemer Gasthuis, Haarlem; Stichting Samenwerkende Ziekenhuizen Noordoost Nederland te Coevoorden, Hardenberg Hoogeveen en Meppel; Afdeling Pathologie, Ijsselmeer Ziekenhuizen, Lelystad; Pathologisch Anatomisch Laboratorium, Winschoten; Laboratorium voor Pathologie, Isala Klinieken Zwolle; Laboratorium voor Pathologie, Alysis Zorggroep Arnhem; Pathologisch Laboratorium Canisius Wilhelmina Ziekenhuis, Nijmegen; Laboratorium voor Pathologie, Jeroen Bosch Ziekenhuis, 's Hertogenbosch. This work was funded by the Netherlands Organization for Health Research and Development (ZonMW grant no. 92003521).

\section{Disclosure/conflict of interest}

The authors declare no conflict of interest.

\section{References}

1 Hacker NF. Vulvar cancer. In: Berek S., Hacker NF, (eds) Practical Gynaecologic Oncology, 4th edn. Lippincott Williams \& Wilkins: Philadelphia, 2005, p 543-583.

2 van de Nieuwenhof HP, van Kempen LC, de Hullu JA, et al. The etiologic role of HPV in vulvar squamous cell carcinoma fine tuned. Cancer Epidemiol Biomarkers Prev 2009;18:2061-2067.

3 Kagie MJ, Kenter GG, Hermans J, et al. The relevance of various vulvar epithelial changes in the early detection of squamous cell carcinoma of the vulva. Int J Gynecol Cancer 1997;7:50-57.

4 Leibowitch M, Neill S, Pelisse M, et al. The epithelial changes associated with squamous cell carcinoma of the vulva: a review of the clinical, histological and viral findings in 78 women. Br J Obstet Gynaecol 1990;97:1135-1139.

5 Maclean AB. Vulval cancer: prevention and screening. Best Pract Res Clin Obstet Gynaecol 2006;20:379-395.

6 Powell JJ, Wojnarowska F. Lichen sclerosus. Lancet 1999;353:1777-1783.

7 van de Nieuwenhof HP, van der Avoort I, de Hullu JA. Review of squamous premalignant vulvar lesions. Crit Rev Oncol Hematol 2008;68:131-156.

8 Wilkinson E. Premalignant and malignant tumors of the vulva. Blaustein's Pathology of the Female Genital Tract, 5th edn. 2002, p 99-150.
9 Carli P, Cattaneo A, De Magnis A, et al. Squamous cell carcinoma arising in vulval lichen sclerosus: a longitudinal cohort study. Eur J Cancer Prev 1995;4: 491-495.

10 van de Nieuwenhof HP, Massuger LF, van der Avoort I, et al. Vulvar squamous cell carcinoma development after diagnosis of VIN increases with age. Eur J Cancer 2009;45:851-856.

11 Fox H, Wells M. Recent advances in the pathology of the vulva. Histopathology 2003;42:209-216.

12 Hart WR. Vulvar intraepithelial neoplasia: historical aspects and current status. Int J Gynecol Pathol 2001;20:16-30.

13 Yang B, Hart WR. Vulvar intraepithelial neoplasia of the simplex (differentiated) type: a clinicopathologic study including analysis of HPV and p53 expression. Am J Surg Pathol 2000;24:429-441.

14 Chiesa-Vottero A, Dvoretsky PM, Hart WR. Histopathologic study of thin vulvar squamous cell carcinomas and associated cutaneous lesions: a correlative study of 48 tumors in 44 patients with analysis of adjacent vulvar intraepithelial neoplasia types and lichen sclerosus. Am J Surg Pathol 2006;30:310-318.

15 van de Nieuwenhof HP, Hebeda KM, Bulten J, et al. Specific intraepithelial localisation of mast cells in differentiated vulvar intraepithelial neoplasia and their possible contribution to vulvar squamous cell carcinoma development. Histopathology 2010;57: 351-362.

16 van der Avoort IAM, van de Nieuwenhof HP, OtteHoller I, et al. High levels of p53 expression correlate with DNA aneuploidy in (pre) malignancies of the vulva. Hum Pathol 2010;41:1475-1485.

17 Scurry J, Campion M, Scurry B, et al. Pathologic audit of 164 consecutive cases of vulvar intraepithelial neoplasia. Int J Gynecol Pathol 2006;25:176-181.

18 Liegl B, Regauer S. p53 immunostaining in lichen sclerosus is related to ischaemic stress and is not a marker of differentiated vulvar intraepithelial neoplasia (d-VIN). Histopathology 2006;48:268-274.

19 Friedrich EGJ. New nomenclature for vulvar disease: Report of the Committee on Terminology. Obstet Gynecol 1976;147:122.

20 Ridley CM, Frankman O, Jones IS, et al. New nomenclature for vulvar disease: international society for the study of vulvar disease.. Hum Pathol 1989;20: 495-496.

21 Casparie M, Tiebosch AT, Burger G, et al. Pathology databanking and biobanking in The Netherlands, a central role for PALGA, the nationwide histopathology and cytopathology data network and archive. Cell Oncol 2007;29:19-24.

22 Regauer S, Liegl B, Reich O. Early vulvar lichen sclerosus: a histopathological challenge. Histopathology 2005;47:340-347.

23 Abell MR. Intraepithelial carcinomas of epidermis and squamous mucosa of vulva and perineum. Surg Clin North Am 2010;45:1179-1198.

24 Hoevenaars BM, van der Avoort I, de Wilde PC, et al. A panel of p16(INK4A), MIB1 and p53 proteins can distinguish between the 2 pathways leading to vulvar squamous cell carcinoma. Int J Cancer 2008;123: 2767-2773.

25 van der Avoort I, Shirango H, Hoevenaars BM, et al. Vulvar squamous cell carcinoma is a multifactorial disease following two separate and independent pathways. Int J Gynecol Pathol 2006;25:22-29. 
26 Sideri M, Jones RW, Wilkinson EJ, et al. Squamous vulvar intraepithelial neoplasia: 2004 modified terminology, ISSVD Vulvar Oncology Subcommittee. J Reprod Med 2005;50:807-810.

27 Renaud-Vilmer C, Cavelier-Balloy B, Porcher R, et al. Vulvar lichen sclerosus: effect of long-term topical application of a potent steroid on the course of the disease. Arch Dermatol 2004;140:709-712.

28 Carlson JA, Ambros R, Malfetano J, et al. Vulvar lichen sclerosus and squamous cell carcinoma: a cohort, case control, and investigational study with historical perspective; implications for chronic inflammation and sclerosis in the development of neoplasia. Hum Pathol 1998;29:932-948.

29 Jones RW, Sadler L, Grant S, et al. Clinically identifying women with vulvar lichen sclerosus at increased risk of squamous cell carcinoma: a case-control study. J Reprod Med 2004;49:808-811.

30 Pinto AP, Lin MC, Sheets EE, et al. Allelic imbalance in lichen sclerosus, hyperplasia, and intraepithelial neoplasia of the vulva. Gynecol Oncol 2000;77: 171-176.

31 Ansink AC, Krul MR, De Weger RA, et al. Human papillomavirus, lichen sclerosus, and squamous cell carcinoma of the vulva: detection and prognostic significance. Gynecol Oncol 1994;52:180-184.

32 Buscema J, Woodruff JD, Parmley TH, et al. Carcinoma in situ of the vulva. Obstet Gynecol 1980;55:225-230.

33 Hording U, Junge J, Daugaard S, et al. Vulvar squamous cell carcinoma and papillomaviruses: indications for two different etiologies. Gynecol Oncol 1994;52: 241-246. 